\section{Improved Blunt-End Cloning by Replacing EcoRV with Eco32I}

BioTechniques 32:1244-1246 (June 2002)

The restriction endonuclease EcoRV, which recognizes and cleaves DNA containing 5'-GATATC-3' sequences, is among the best characterized and most frequently used bluntend cutting restriction enzymes (2). Its recognition site is present in many cloning vectors currently in use. Com pared with that of cohesive ends, bluntend ligation is generally more difficult because a higher number of background colonies is formed that result from self-ligation of vector molecules (1). We (and others) have found that when using EcoRV even "white color" selection often fails so that one ends up with a large number of apparently positive (white) colonies. Here we demonstrate that this problem can be reduced if one uses Eco32I, an isoschizomer of EcoRV (3), instead.

To compare the cloning efficiencies of EcoRV and Eco32I, we chose to insert a blunt-ended PCR fragment derived from the human $\beta$-catenin gene $C T N N B 1$ into the GATATC site of vector $\mathrm{pZErO}^{\mathrm{TM}} 2.1$ (Invitrogen, Carlsbad, CA, USA). The GATATC site of pZErO 2.1 is an integral part of an open reading frame encoding a lacZ $\alpha / \mathrm{ccdB}$ fusion protein. Insertion of a heterologous DNA fragment disrupts this open reading frame and results in both loss of $\beta$-galactosidase as well as rescue from the ccdB suicide gene activity. Thus, using pZErO 2.1, self-ligated vector molecules are efficiently selected against, thereby obviating the need for dephosphorylation of vector DNA before blunt-end ligation.

Genomic DNA was isolated from human embryonic kidney-derived 293 cells, and a 675-bp DNA fragment derived from the human $\beta$-catenin gene CTNNB 1 was amplified by PCR using primers bcat-fwd1 (5'-ACATTTCCA ATCTACTAATG-3') and bcat-rev1 (5'AAGTTCTGCATCATCTTGATAG-3'). The resulting PCR fragment contains multiple stop codons in all six possible reading frames, ensuring that inactivation of the $c c d \mathrm{~B}$ suicide gene occurs

Table 1. Cloning Efficiencies

\begin{tabular}{|lccccc|}
\hline \multicolumn{3}{|c}{ EcoRV } & & \multicolumn{2}{c|}{ Eco32l } \\
\cline { 2 - 3 } \cline { 5 - 5 } & $\begin{array}{c}\text { No. }{ }^{\text {a }} \text { of Insert- } \\
\text { Positive Colonies }\end{array}$ & $\begin{array}{c}\text { Total No. } \\
\text { of Colonies }\end{array}$ & $\begin{array}{c}\text { No. of Insert- } \\
\text { Positive Colonies }\end{array}$ & $\begin{array}{c}\text { Total No. } \\
\text { of Colonies }\end{array}$ \\
\hline Vb & 0 & $157 \pm 15$ & & 0 & $65 \pm 9$ \\
V + Fc & $24(15 \%)$ & $157 \pm 15$ & & $25(38 \%)$ & $66 \pm 4$ \\
a Values are the means of three independent experiments. \\
bV, vector \\
cF, CTNNB1 fragment insert
\end{tabular}

upon insertion of the fragment in either orientation and any reading frame. The PCR product was gel-purified and extracted using Concert ${ }^{\mathrm{TM}}$ Gel Extraction System (Invitrogen) as recommended by the manufacturer. For cloning, the purified PCR fragment was made blunt-ended by treatment with T4 DNA polymerase and column-purified using High Pure PCR Product Isolation kit (both from Roche Applied Science, Basel, Switzerland).

To generate vector suitable for ligation to the CTNNB1 insert, $500 \mathrm{ng}$ pZErO 2.1 DNA were digested for $60 \mathrm{~min}$ at $37^{\circ} \mathrm{C}$ with $10 \mathrm{U}$ EcoRV (Roche Applied Science) or $10 \mathrm{U}$ Eco32I (MBI Fermentas, Vilnius, Lithuania) using supplied buffers. The digested vector was purified using the High Pure PCR Product Isolation kit.

A $15-\mu \mathrm{L}$ ligation mixture was then set up in a reaction containing $10 \mathrm{ng}$ linearized vector, $10 \mathrm{ng}$ PCR fragment (molar end ratio 1:5), $4 \mathrm{U}$ T4 DNA ligase (Roche Applied Science) in $1 \times$ ligase buffer. A control reaction lacking PCR fragment was done in parallel. All ligations were incubated at $16^{\circ} \mathrm{C}$ for $16 \mathrm{~h}$.

One microliter of each ligation mixture was transformed into $50 \mu \mathrm{L}$ chemically competent One Shot ${ }^{\circledR}$ Top 10 cells (Invitrogen), and the cells were spread on LB agar plates containing $50 \mu \mathrm{g} / \mathrm{mL}$ kanamycin. To determine the percentage of true recombinant clones, we prepared colony lifts using Biodyne ${ }^{\circledR}$ A filters (Pall, East Hills, NY, USA), which were subsequently hybridized to a radioactively labeled probe generated by amplification of an internal 224-bp fragment of CTNNB1 using primers bcat-fwd2 (5'-GATTTGATGGAGTTGGACATGG-3') and bcat-rev2 (5'GCTACTTGTTCTTGAGTGAAGG$\left.3^{\prime}\right)$. Hybridization-positive colonies were counted. We did not employ "white color" selection to check for the presence of inserts because in many previous experiments we found that self-ligated vector molecules lacking inserts may give rise to white colonies.

No insert-containing colonies were obtained in the ligation reactions "vector alone" (Table 1). Ligation of the blunt-ended fragment into vector DNA cut by either enzyme, Eco32I or EcoRV, resulted in the same absolute number of insert-containing clones; however, when Eco32I-digested vector was used, a higher proportion of insertpostive clones $(38 \%)$ was obtained as compared to EcoRV (15\%). The difference found was highly significant (twosided $P$ value $<0.001$; Fisher's exact test). In three independent experiments, the use of vector DNA prepared by restriction with EcoRV resulted in the formation of a significantly higher number of background colonies (Table 1).

To investigate the possible reason for the observed difference in the formation of kanamycin-resistant colonies, we checked the integrity of the GATATC cloning site of clones obtained after cutting and simple self-ligation by sequence analysis. Ten clones each from EcoRV and Eco32I "vector alone" plates were picked, grown, and plasmid DNA was extracted using the High Pure Plasmid DNA Isolation kit. Sequencing reactions were set up following a dye terminator protocol $\left(\right.$ BigDye ${ }^{\mathrm{TM}}$; Perkin Elmer, Boston, MA, USA), following the manufacturer's instructions. Sequencing primers were standard M13 forward and reverse primers.

Sequence analysis revealed a frequent single-nucleotide deletion within the vector's cloning site that changed the GATATC motif to GAATC (GATTC in the complementary strand; 
Table 2. Frequent Single-Nucleotide Deletions in Self-Ligated Eco RV Sites

\begin{tabular}{|c|c|c|c|}
\hline \multicolumn{2}{|c|}{ EcoRVa } & \multicolumn{2}{|c|}{$\left.E c 032\right|^{b}$} \\
\hline $\begin{array}{l}\text { Sample No. } \\
\text { Controlc }\end{array}$ & $\begin{array}{c}\text { Sequencing Result } \\
\text { GATATC }\end{array}$ & $\begin{array}{l}\text { Sample No. } \\
\text { Control }\end{array}$ & $\begin{array}{c}\text { Sequencing Result } \\
\text { GATATC }\end{array}$ \\
\hline 1 & GA ATC & 1 & GA ATC \\
\hline 2 & GATTC & 2 & deld:f1e \\
\hline 3 & GATTC & 3 & del:f1 \\
\hline 4 & GATTC & 4 & del:ccdB \\
\hline 5 & GATTC & 5 & del:M13revg \\
\hline 6 & GATTC & 6 & del:M13rev \\
\hline 7 & GATTC & 7 & del:M13rev \\
\hline 8 & GATTC & 8 & del:M13rev \\
\hline 9 & GA ATC & 9 & del:f1 \\
\hline 10 & GA ATC & 10 & del:ccdB \\
\hline 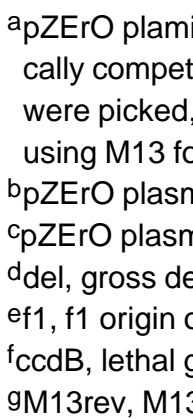 & $\begin{array}{l}\text { DNA was cut with Eco } \\
\text { t One Shot Top } 10 \mathrm{~F}^{\prime} \mathrm{c} \\
\text { nd plasmid DNA was } \\
\text { vard and reverse prime } \\
\text { DNA was cut with EC } \\
\text { uncut } \\
\text { tion extending into : se } \\
\text { replication } \\
\text { ne ccdB } \\
\text { everse priming site }\end{array}$ & $\begin{array}{l}\text { re-ligated, and } \\
\text { Ten individual } \\
\text { ted and subjec } \\
\text { and treated as } \\
\text { nce indicated }\end{array}$ & $\begin{array}{l}\text { ansformed into chemi- } \\
\text { ecombinant clones } \\
\text { do DNA sequencing } \\
\text { described earlier. }\end{array}$ \\
\hline
\end{tabular}

Table 2). The specific (-1) frame shift created by this mutation results in the immediate rescue from the ccdB suicide gene activity, thereby allowing the outgrowth of false-positive colonies. Such single-nucleotide deletions were found in all clones after cutting and self-ligation with EcoRV. In contrast, only one of 10 clones derived from Eco32I-treated vector displayed this type of single-nucleotide deletion. However, the majority of false-positive clones obtained in these experiments were found to contain large deletions ( 202 to $849 \mathrm{bp}$ ) that extended into the $c c d \mathrm{~B}$ gene, the $\mathrm{M} 13$ reverse sequencing primer binding site, or the $\mathrm{f} 1$ origin of replication, thereby removing part or all of the $c c d \mathrm{~B}$ gene. Since the overall number of such latter clones was found to be significantly lower than false-positive clones derived from EcoRV-treated vector, the mutational mechanism leading to single-nucleotide deletions seems to be specifically associated with the use of EcoRV and, thus, is mainly responsible for the increased number of background colonies.
We made similar observations with $E c o$ RV enzyme aliquots from different lots from the same as well as from different suppliers (not shown). Therefore, we conclude that the observed singlenucleotide deletions are likely the result of an intrinsic activity associated with the EcoRV restriction enzyme itself. Cleavage of GATATC sites by EcoRV but not Eco32I may specifically lead to partially damaged DNA ends that allow self-ligation but prevent the insertion of heterologous blunt-ended fragments. One possible explanation would be that the removal of the terminal base pair is accompanied by a dephosphorylation event affecting the adjacent $5^{\prime}$ phosphate group. Removal of both terminal base pairs then may occur but would result in a completely dephosphorylated vector that can no longer re-ligate. Only those molecules that lack one nucleotide and which are partially dephosphorylated would then give rise to background clones. Alternatively, the removal of the terminal base pair may occur only immediately after cleavage and would be caused by a molecule of
EcoRV sticking to one end of the linearized DNA fragment. Whatever the underlying mechanism may be, substitution of EcoRV by Eco32I should prove helpful in cloning experiments involving GATATC sites in everyday laboratory practice.

\section{REFERENCES}

1.Ianulaitis, A.A., P.S. Stakenas, M.P. Piatrushite, I.u.B. Bitinaite, and S.I. Klimashauskas. 1984. Specificity of new restrictases and methylases. Unusual modification of cytosine at position 4. Mol. Biol. (Mosk.) 18:115-129.

2.Pingoud, A. and A. Jeltsch. 1997. Recognition and cleavage of DNA by type-II restriction endonucleases.Eur. J. Biochem. 246:1-22.

3.Struhl, K. 1994. Construction of hybrid DNA molecules, p. 3.16.1-3.16.11. In F.M. Ausubel, R. Brent, R.E. Kingston, D.D. Moore, J.A. Smith, J.G. Seidman, and K. Struhl (Eds.), Current Protocols in Molecular Biology. John Wiley \& Sons, New York.

Address correspondence to Dr. Robert Koesters, Division of Molecular Pathology, Department of Pathology, University Hospital of Heidelberg, Im Neuenheimer Feld 220/221, 69120 Heidelberg, Germany. email: r.koesters@dkfz.de

Received 6 February 2002; accepted 14 March 2002.

\section{Robert Koesters and Magnus von Knebel Doeberitz \\ University Hospital of Heidelberg Heidelberg, Germany}

For reprints of this or any other article, contact Reprints@BioTechniques.com 